Carpenter et al. (1956) have suggested that the lower values for M.V.V. found in miners with clear films than in those with simple pneumoconiosis might be due to generalized emphysema in the former group, and Leathart (1959) supported this view. The finding of an increased residual volume among such miners in the present study is also in keeping with this suggestion. A possible explanation for this paradox has been offered by Rappaport (1966), who suggested that emphysema could mask the shadows cast by dust in the lungs. If emphysema is the cause of the increased residual volume found among the miners in the present study, then its physiological manifestations differ from those reported by Fletcher et al. (1963) for patients with primary emphysema. Fletcher's patients showed an increase in residual volume and R.V./T.L.C.\% comparable to that found among the miners in the present series, but in addition there was severe airways obstruction and impairment of the transfer factor.

In their account of the pathogenesis of focal emphysema due to coal dust, Heppelston and Leopold (1961) pointed out that, initially, disruption of the alveoli is not a feature of this condition. Moreover, the bronchial smooth muscle is atrophic or absent and expiratory contraction of the bronchioles is diminished or abolished. Heppleston and Leopold attribute the alveolar dilatation to inspiratory traction upon the alveoli surrounding the deposits of dust rather than to expiratory airway obstruction. In the present investigation the finding among the coal miners of an increased residual volume with relatively less evidence of expiratory airway obstruction or impairment of gas transfer is compatible with Heppleston and Leopold's observations in focal emphysema. However, a normal transfer factor does not necessarily exclude alveolar destruction, and no conclusions can be drawn regarding the anatomical significance of our physiological findings. It is clear that a careful necropsy examination of the lungs of miners in whom physiological tests have been done during life is needed.

\section{Summary}

The physiological findings in 17 coal miners referred to a pulmonary function laboratory because of unexplained dyspnoea are compared with the findings in 15 patients referred with chronic non-specific lung disease and five normal subjects of the same age group.
The two groups of patients showed a comparable increase in residual volume, total lung capacity, and R.V./T.L.C.\%, but expiratory airways obstruction and impairment of gas transfer were considerably less in the group of miners than in the patients with chronic non-specific lung disease.

The increase in residual volume was greater in the miners with clear radiographs than in those with simple pneumoconiosis. The increase in residual volume was also greater in those with a reduced M.V.V. and a high grade of dyspnoea, but it could still be detected in breathless miners with a normal M.V.V. and no evidence of expiratory airways obstruction.

It is suggested that the physiological findings in this group of miners are compatible with some of the reported pathological features of focal emphysema due to coal dust, but no conclusions can be drawn until necropsy studies are available for miners investigated during life.

We are indebted to the technical staff of the regional pulmonary function laboratory, Broadgreen Hospital, for their assistance in carrying out the tests reported in this paper; to Dr. James Carmichael, who read the chest radiographs; and to the consultant physicians who referred the patients for investigation. We are especially grateful to Dr. James MacArthur for his help and encouragement.

\section{REFERENCES}

Baldwin, E. de F., Cournand, A., and Richards, D. W., jun. (1948), Medicine (Baltimore), 27, 243.

Brasseur, L. (1963). Lexploration fonctionnelle pulmonaire dans la pneumoconiose des houilleurs. Brussels.

Burrows, B., Niden, A. H., Fletcher, C. M., and Jones, N. L. (1964), Amer. Rev. resp. Dis., $90,14$.

Carpenter, R. G., Cochrane, A. L., Gilson, J. C., and Higgins, I. T. T (1956). Brit. \%. industr. Med., 13, 166.

Ciba Guest Symposium (1959). Thorax, 14, 286. (1963). Quart. F. Med., 32, 33 .

Gilson, J. C., and Hugh-Jones, P. (1955). Spec. Rep. Ser. med. Res. Coun. (Lond.), No. 290

Heppleston, A. G., and Leopold, J. G. (1961). Amer. 7. Med., 31, 279.

Higgins, I. T. T., Oldham, P. D., Cochrane, A. L., and Gilson, J. C (1956). Brit. med. 7., 2, 904.

Leathart, G. L. (1959). Brit. F. industr. Med., 16, 153.

Ogilvie, C. M., Forster, R. E., Blakemore, W. S., and Morton, J. W. (1957) \%. clin. Invest., 36, 1.

Harris, L. H., Meecham, J., and Ryder, G. (1963). Brit. med. f., 1 , 1111.

Rappaport, I. (1966). Ibid., 1, 1356.

\title{
Psychiatric Study of a Consecutive Series of 34 Patients with Ulcerative Colitis*
}

\author{
FRED FELDMAN, M.D.; DAVID CANTOR, M.D. ; SIDNEY SOLL, M.D. ; WILLIAM BACHRACH, M.I)
}

Brit. med. F., 1967, 3, 14-17

The purpose of this study is to evaluate the role of psychiatric factors in the causation of ulcerative colitis by survey of a fairly long unselected series. Ulcerative colitis is still one of the most enigmatic of diseases, despite its position, paradoxically, as the " classic" psychosomatic illness. Its cause is believed by most gastroenterologists to be unknown, yet a large number of reports by psychiatrists discuss it as an unquestionably psychosomatic illness. The studies by physicians and surgeons of such medical factors as cause, course, complications, and drug treatment have been for the most part cautious, uncertain, and qualified (Crohn and Yarnis, 1951 ; Michener et al., 1961 ; Hijmans and Enzer, 1962 ; Korelitz et al., 1962 ; Edwards and Truelove, 1963,

* From the Department of Medicine and Department of Psychiatry, Cedars-Sinai Medical Center, Mount Sinai Division, Los Angeles, California.
1964 ; Rhodes and Kirsner, 1965). On the other hand, reports by psychiatrists of much smaller series (Engel, 1961 ; Finch and Hess, 1962 ; Fullerton et al., 1962 ; Powles, 1964), sometimes random and unselected, have used such terms as "constantly show severe psychopathology," "uniformly show pathology," " in every case," and "the evidence is overwhelming, incontrovertible."

We are aware that psychiatrists recognize that the disease is one which may be multifactorial in origin, and that some of them regard the psychogenic component as only one factor out of many. Nevertheless, the presence of severe psychopathic disease is so consistently described that the impression is gained from leading psychiatric papers that an emotional component is necessary for the condition to exist. Both sophisticated psychiatric readers and general physicians seem to derive this 
notion from the psychiatric literature. One of the papers cited above (Fullerton et al., 1962), for example, stated specifically that ulcerative colitis " represented a morbid grief reaction," and other papers circuitously or directly imply that emotional conflicts are a requisite though perhaps only partial cause.

The concept of "psychosomatic disease" has become a blurred one, and the term is used in three different ways:

(1) The "true" or "strict" psychosomatic diseases are those which must have a psychogenic component as part of the cause, or they cannot exist. The usual lists of " true psychosomatic illness" include duodenal ulcer, ulcerative colitis, hypertension, asthma, and neurodermatitis.

(2) Illnesses which appear physical in origin but may be exacerbated, triggered, or hastened by psychogenic factors (one might postulate heart disease in this category) would be regarded as not "truly psychogenic" illnesses but ones influenced by psychophysiological factors. Some physicians feel that the diseases listed under paragraph (1) above may often belong only to this second level, and that no true psychosomatic disease has as yet been verified.

(3) Illnesses whose cause and physical pathology are at present unknown-for example, most headaches, other pains-may be designated as "possibly psychosomatic." No proof exists.

The psychosomatic literature is often vague and confusing in its criteria for validating the psychogenic component, and thus proving it an indispensable element.

We are suggesting seven criteria in an attempt to summarize all indices used by psychiatrists to prove that a psychosomatic disease may exist. The seven criteria are: (1) a characteristic personality disorder of moderately severe to severe degree, or other definite psychiatric diagnosis; (2) a clearly emotional precipitating factor, chronologically related to the illness; (3) general stress, not necessarily symbolically related to the illness but perhaps cumulative; (4) basic emotional problems of long or short duration, with significant background features symbolically related to the illness ; (5) alternation of symptoms, or syndrome shift; (6) characteristic patterns of illness in the life history ; and (7) efficacy of psychotherapy.

\section{Material}

Thirty-four patients with ulcerative colitis were studied. Every known patient with ulcerative colitis admitted to the gastroenterology service between August 1964 and June 1966 was included.

Tables I and II list age group, sex, severity of disease, number of crises, and patients who have been treated psychiatrically.

TABle I.-Age Groups and Sex Distributions of 34 Ulcerative Colitis

\begin{tabular}{c|c|c|c} 
& \multicolumn{3}{|c|}{ Patients } \\
Age Group & No. of Patients & Males & Females \\
\hline $10-20$ & 9 & 2 & 7 \\
$21-30$ & 10 & 4 & 6 \\
$31-40$ & 8 & 5 & $\frac{3}{1}$ \\
$41-50$ & 5 & -1 & - \\
$51-60$ & 1 & 17 & 17 \\
$61-70$ & 34 & & 5 \\
\hline Total & & 17 & \\
\hline
\end{tabular}

TABle II.-Other Clinical Data on 34 Ulcerative Colitis Paiients

Severity of disease

No. of crise:

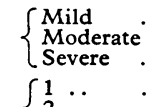

$\begin{cases}1 & \cdots \\ 2 & \cdots\end{cases}$

More than 2

Able to function normally

Function normally but frequen

visits to doctors

Not known

Response to medical treatmen

No of patients with ileostomy

Nc. of patients who received psychiatric treatment
Two types of " control" groups were used. The first can be regarded as a control group only in the loosest sense, since it consisted of the general population, divided into normal and abnormal according to arbitrary criteria. The second control group comprised 74 patients. These were the first 74 consecutive patients admitted to the gastroenterology service while the study on ulcerative colitis was in process. No patients with large-intestine disease or regional enteritis were included.

\section{Method}

The team members consisted of a psychiatrist, a physician, and two gastroenterologists, one of whom was a Fellow in Psychosomatic Medicine. All four have had a long-standing interest in psychosomatic disease. (The psychiatrist is also a psychoanalyst, and a member of the American Psychoanalytic Association.)

Each patient first had two standard psychiatric interviews, of the free-association type, but eventually including a discussion of sufficient current and past material to yield data for scoring about 65 variables considered salient for personality evaluation. The first interview usually lasted two to three hours, and was conducted by the Fellow. He then reported his findings to the team in detail. The team, including the psychiatrist plus the Fellow and one of the other physicians, then conducted the second interview, which lasted about an hour. Subsequently, the team, including the psychiatrist, almost always saw the patient a second time, and then as often as possible during the stay in hospital. The Fellow continued to see each patient every day, and reported to the team twice a week. The minimum amount of psychiatric time spent with and discussing each patient was five to six hours, and the average 10 to 12 hours. In some cases the time spent was longer, since, for example, three patients remained in the hospital several months.

The psychiatric evaluation took into consideration all the descriptive and dynamic variables which a complete evaluation requires. Among them were symptoms, cognition, ego strengths, defensiveness, acting out, dependence, external problems, attitude toward illness, past history, anxiety, depression, personality type, background, parents, role reversal, siblings, psychosomatic relationships, and many others. All 65 variables were scored in every case, on a 1 to 5 basis, as explained below. As noted above, the scoring for the seven criteria was undertaken cautiously. Broad limits for "normality" were used. The criteria for placing a patient in the "predominantly normal," " normal aggressive," or " normal passive" groups were: (1) no moderately severe or severe personality disorders; (2) average or better ego strengths in the great majority of the 14 categories of ego strengths in the inventory ; (3) no severe emotional problems or conflicts which would have required psychotherapy were it not for the physical illness ; (4) no diagnosis of psychosis, impulse disorder, or moderate to severe psychoneurosis or depression; (5) evidence of constructive handling of life's anxieties and problems ; and (6) no significant patterns of hypochondriasis or incapacity due to unexplained illness of any sort.

The entire process by which the decision about normality was made is too compendious to describe. However, it was thought to be so important that a 200-page handbook has been written, and used, to evaluate all of the 65 variables in the inventory. Criteria for scoring each variable as $1,2,3,4$, or 5 were given.

Each patient was diagnosed as "normal" or "abnormal" in each category of the protocol. "Normal" was scored as 3, 4 , or 5 , "abnormal " as 1 or 2 . A normal distribution curve was used (Fig. 1). This curve refers to the general populationthat is, an arbitrary assumption has been made that approximately $70 \%$ of the general population are "normal" and $30 \%$ 
definitely "abnormal." We recognize the danger that such a decision may appear uncompromising and high-handed. We tried to take into consideration, for each patient, a comparison not only with the general population but also with the patient's cultural group.

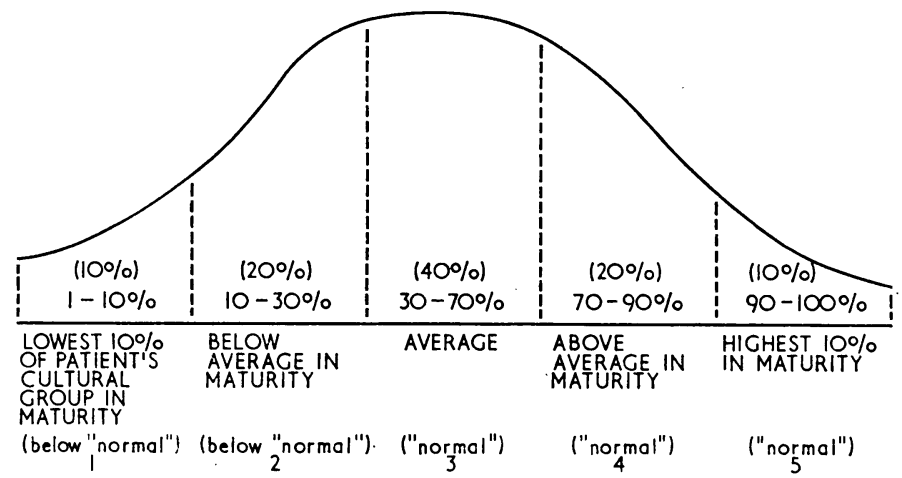

FIG. 1.-Normal distribution curve.

The final designation of normality or abnormality was made by discussion among all four investigators. No patient was placed in the normal group unless all four agreed.

\section{Results in Ulcerative Colitis Patients}

Personality Types and Psychiatric Illness.-Twenty-nine of the patients were regarded as essentially "normal" and five as "abnormal." The five abnormal personality types included one or more of the following character disorders to a significant degree: inadequate, infantiie, passive, schizoid, depressive, or dependent. There were among the "normal" personalities mild to moderate personality characteristics in this incidence: passive-dependent, 8 ; passive-aggressive, 5 ; anxious, 1. Fifteen were classed as predominantly normal-that is, to have no or very mild character disorders. There was one psychopathic personality who was also diagnosed as "schizoid." There were no psychoses, severe psychoneuroses, or severe depressions.

Fig. 2 shows the data given above, and also the following precipitating factors and stresses.

Precipitating Factors and Chronological Relations.-In only 4 out of the 34 cases was a significant precipitating factor thought to have occurred close in time to the first attack of ulcerative colitis. In three cases there was a possible substantial emotional conflict. In 15 cases a moderately eventful emotional factor was present within six months of a relapse of the disease but not before its first occurrence. It must be noted that by this time almost every patient had been alerted to the "probable" emotional origin of ulcerative colitis, and was therefore often impressionable to what might otherwise be considered to be normal events. (a) No instances of extreme separation anxiety were found. No specific symbolic separation factors were regarded as pivotal. (b) There were no instances where fear of taking forward steps in career or marriage seemed crucial. In general, all 29 classed as " normal " were thought to have handled adolescent or adult responsibilities fairly well. There appeared to be no excessive fear that outgoing or aggressive behaviour was dangerous or destructive, and many of them had played football and other sports, had "hit back" when hurt, and had shown an ability to reach out to forward their ambitions when necessary. In general, then, our cases did not show the consistent presence of important precipitating factors.

General Conscious Stress, Not Necessarily Symbolically Related to the Illness, but Perhaps Cumulative.-This factor is difficult to evaluate, since every sensitive human being is aware of stress. We tried to be realistic in evaluating the degree of stress in a patient's life, and regarded as significant any degree of conflict beyond the average. In only five instances was a moderate to severe degree of stress present before the onset of the first attack. There were no other instances of "extreme stress" in the other 33 patients in the approximately five years preceding onset of the illness. In nine cases a moderate to moderately severe degree of stress was present before a relapse. There were no cases of extreme stress before relapses.

Basic or Nuclear Emotional Problems, of Long or Short Duration, with Significant Background Features, Symbolically or Unconsciously Related to the Illness.-There were 14 cases in which the total background, or dynamic, factors were such as to suggest the "possibility" of nuclear conflicts which might express themselves in somatic illness, if such conversion is thought possible. In no case was it felt that any of the possible nuclear conflicts showed a demonstrable symbolic relation to the ulcerative colitis. There were no instances of severe role reversal in childhood, for example. The extent of unusual aggressiveness in mothers and passivity in fathers was about average for the population. The type of "helplessness" described by Engel $(1954,1955,1958)$ was considered to be present only as secondary to the illness itself. There was often no helplessness even in seriously ill patients. We found no notable prevalence of problems of bowel training or bowel preoccupation in the family.

Alternation of Symptoms, or Syndrome Shift.-No alternation of either psychiatric or physical symptoms with the ulcerative colitis was encountered in the patients' history or in their hospital course. Headaches were a complaint in six cases, but without significant reference to the severity of the ulcerative colitis symptoms. Mild to moderate depression was present in four cases; there was no alternation with the symptoms of colitis; if anything, the depression was severe only when the colitis symptoms were most severe.

Characteristic Patterns of Illness in the Life History.-There were a number of cases of mild hypochondriasis, but none was outstanding. Most of the patients had had relative freedom from physical and psychiatric illness.

Efficacy of Psychotherapy.-Of the 34 patients seven had undergone fairly extensive psychiatric treatment lasting from several months to eight years. In three cases it had aided the patients' adjustment to the disease, but in none did it have an appreciable effect on the course of the illness.

\section{Results in Control Group}

The patients in this group were as carefully examined and followed as were the patients with ulcerative colitis. The results are not described in detail here, but are compared with those of the ulcerative colitis patients in Fig. 2. In general, the control patients showed as much psychopathology as, or more than, the ulcerative colitis cases.

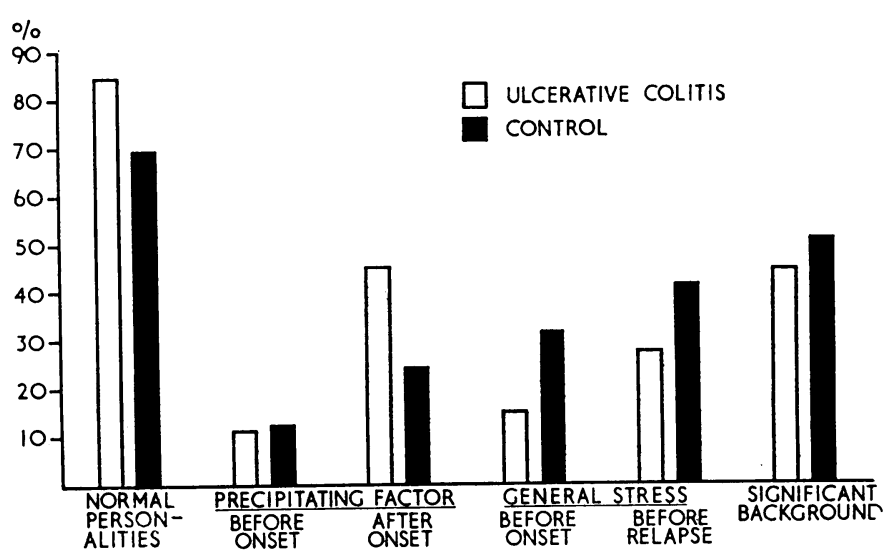

FIG. 2.-Comparison of frequency of occurrence of the mention psychiatric factors between 34 ulcerative colitis and 74 control patient 


\section{Discussion}

Essentially the 34 ulcerative colitis patients fall within the distribution of "normality" in our society as we have defined it. The question of whether or not an accurate psychiatric appraisal can be made in one or two interviews, plus observation of the patient for a brief period in the hospital, is a valid one. It may be answered in part by the experience of the psychiatrist in another situation where a similar type of evaluation proved successful. This involved eight years of experience in a low-cost psychoanalytic clinic, where patients were screened in one or two interviews by a team of two to four psychiatrists.

Our review of the literature became so lengthy that we have included it in a companion paper. In general, we found that our results were different from those of most psychiatrists but similar to those of the gastroenterologists.

Of approximately 300 reports a year in the world literature we estimate that about $10 \%$ are devoted primarily to the psychogenic aspects, another 20 to $30 \%$ mention psychiatric factors with uncertainty or partial acceptance, and the remaining 60 to $70 \%$ omit psychiatric aspects almost completely. Most of the psychiatric reports are subject to several criticisms. Many of them deal with only one or two patients analysed at great length, little attention being paid to the medical irregularities of the illness. Many of the studies are retrospective (Daniels et al., 1962 ; Fullerton et al., 1962 ; Langford, 1964), or deal with relatively large groups gathered from questionaries and not evaluated personally by the team (Weinstock, 1962). Many studies are of cases selected by other physicians and then referred to psychiatrists (Mohr, 1960; Sperling, 1960). In other instances no controls were used, or the criteria for emotional evaluation were not given, or cases were reported only if they had been in treatment (O'Connor et al., 1964).

So far as we can tell, our series of 34 is the first in which a relatively large, consecutive, and unselected group of cases has been studied by the same team, using the same methods, planned in advance. There are two other studies in the literature, of about the same length, which may be comparable (Wittkower, 1938 ; Langford, 1964). Their cases were investigated less intensively than ours.

In our review we encountered the phenomenon of what might be called the innocent acceptance of previous reports (McDermott, 1966). Another observation is that in some of the papers written by teams of gastroenterologists and psychiatrists (or psychologists) there appears to be a split in the reactions of the two groups about the patients (Ehrenpreis et al., 1960).

\section{Summary and Conclusions}

Thirty-four consecutive unselected cases of ulcerative colitis have been studied psychiatrically. They appeared to present essentially the usual distribution of emotional problems to be expected in a group of that size. This statement must be modified by several qualifications, particularly the difficulty in assessing deeper problems with our type of interviews. As many as possible of the emotional factors relating to psychosomatic illness mentioned in the psychiatric literature were found not to apply in any significant degree. Our series is small and no definitive conclusions are drawn. We do, however, raise the question whether the disease should be regarded as "psychosomatic."

Our results are presented with concern and caution, since large philosophical questions are raised. These questions concern: (1) the concept of "normality" and our recognition that the assumption of $70 \%$ " normality" is open to criticism ; (2) the reliability of diagnostic criteria in psychiatry as compared with other fields of medicine; (3) the symbolic significance of diarrhoea in ulcerative colitis, taking into consideration the fact that the motility of the bowel in ulcerative colitis patients is different from that found in "functional " colonic disorders (Almy et al., 1949 ; Chaudhary and Truelove, 1961); and (4) the central problem of whether primary psychosomatic disease exists, and, if so, how it can be explained.

\section{REFERENCES}

Almy, T. P., Kern, F., jun., and Tulin, M. (1949). Gastroenterology, 12,425 .'

Chaudhary, N. A., and Truelove, S. C. (1961). Ibid., 40, 1, 18.

Crohn, B. B., and Yarnis, H. (1951). N.Y. St. F. Med., 51, 2129.

Daniels, G. E., O'Connor, J. F., Karush, A., Moses, L., Flood, C. A. and Lepore, M. (1962). Psychosom. Med., 24, 85.

Edwards, F. C., and Truelove, S. C. (1963). Gut, 4, 299.

- (1964). Ibid., 5, 1.

Ehrenpreis, T., Ericsson, N. O., Billing, L., Lagercrantz, R., and Rudhe, U. (1960). Acta paediat. (Üppsala), 49, 810.

Engel, G. L. (1954). Amer. F. Med., 16, 416.

- (1955). Ibid., 19, 231.

- (1958). Amer. 7. dig. Dis., 3, 315.

- (1961). Gastroenterology, 40, 313.

Finch, S. M., and Hess, J. H. (1962). Amer. F. Psychiat., 118, 819.

Fullerton, D. T., Kollar, E. J., and Caldwell, A. B. (1962). F. Amer. med. Ass., 181, 463.

Hijmans, J. C., and Enzer, N. B. (1962). Pediatrics, 29, 389.

Korelitz, B. I., Gribetz, D., and Danziger, I. (1962). Ann. intern. Med., $57,582$.

Langford, W. S. (1964). Clin. Proc. Child. Hosp. (Wash.), 20, 89.

McDermott, J. F. (1966). Psychosomatics, 7, 163.

Michener, W. M., Gage, R. P., Sauer, W. G., and Stickler, G. B. (1961) New Engl. अ. Med., 265, 1075.

Mohr, G. J. (1960). Amer. f. Gastroent., 34, 42.

O’Connor, J. F., Daniels, G., Karush, A., Moses, L., Flood, C., and Stern, L. O.' (1964). Amer. F. Psychiat., 120, 738.

Powles, W. E. (1964). Canad. Psychiat. Ass. 7., 9, 51.

Rhodes, J. B., and Kirsner, J. B. (1965). Surg. Gynec. Obstet., 121, 1303 .

Sperling, M. (1960). Int. F. Psycho-Anal., 41, 450.

Weinstock, H. I. (1962). F. psychosom. Res., 6, 243.

Wittkower, E. (1938). Brit. med. F., 2, 1356. 